\title{
THE EFFECT OF RELIGIUSITY, TRANFORMATIONAL LEADERSHIP AND DEMOGRAPHY ON ORGANIZATIONAL CITIZENSHIP BEHAVIOR (OCB)
}

\author{
Annisa Ayu Budhiarti \\ annisaayubudhiarti@yahoo.com \\ Anggota HIMPSI Provinsi Banten
}

\author{
Yunita Faela Nisa \\ yunita.faela@uinjkt.ac.id \\ Fakultas Psikologi UIN Syarif \\ Hidayatullah Jakarta
}

\begin{abstract}
This research was conducted to find out the significance of the influence of religiosity, transformational leadership style and demography on organizational citizenship behavior $(O C B)$ on 138 state-owned employees in PT. Surveyor Indonesia and 88 private employees in the Household Pesticide Industry Company. Sampling conducted using non probability sampling. The measuring tool used in this study took from Huber (2012) figures to measure religiosity, Rafferty and Griffin (2014) to measure transformational leadership styles. Test the validity of measuring instruments using Confirmatory Factor Analysis (CFA) techniques and data analysis techniques using multiple regression analysis techniques. The results of this study indicate that there is a significant influence of religiosity, transformational leadership style and demography on organizational citizenship behavior $(O C B)$ by contributing $26.2 \%$. That is, the proportion of variance of organizational citizenship behavior explained together by religiosity, transformational leadership style and demography is $26.2 \%$ while the other $73.8 \%$ is influenced by other variables beyond this study.
\end{abstract}

Keyword: religiosity, transformational leadership style, demography, Organizational Citizenship Behavior (OCB)

\begin{abstract}
Abstrak
Penelitian ini dilakukan untuk mengetahui signifikansi pengaruh religiusitas, gaya kepemimpinan transformasional dan demografi terhadap Organizational Citizenship Behavior (OCB) pada 138 karyawan BUMN di PT. Surveyor Indonesia dan 88 karyawan swasta di Perusahaan Industri Pestisida Rumah Tangga. Pengambilan sampel yang dilakukan menggunakan non probability sampling. Alat ukur yang digunakan dalam penelitian ini mengambil dari tokoh Huber (2012) untuk mengukur religiusitas, Rafferty dan Griffin (2014) untuk mengukur gaya kepemimpinan transformasional. Uji validitas alat ukur menggunakan teknik Confirmatory Factor Analysis (CFA) dan teknik analisis data menggunakan teknik analisis regresi berganda. Hasil penelitian ini menunjukkan bahwa terdapat pengaruh yang signifikan dari religiusitas, gaya kepemimpinan transformasional dan demografi terhadap Organizational Citizenship Behavior (OCB) dengan memberikan kontribusi sebesar 26,2\%. Artinya, proporsi varians dari organizational citizenship behavior yang dijelaskan secara bersama-sama oleh religiusitas, gaya kepemimpinan transformasional dan demografi adalah sebesar $26,2 \%$ sementara $73,8 \%$ lainnya dipengaruhioleh variabel lain diluar penelitian ini.
\end{abstract}

Katakunci: religiusitas, gaya kepemimpinan transformasional, demografi, Organizational Citizenship Behavior (OCB)

Diterima: 11 April 2017 Direvisi: 17 Mei 2017

Disetujui: 27 Juni 2017 


\section{PENDAHULUAN}

Perusahaan mempunyai tujuan untuk meningkatkan efisiensi dan kemampuan untuk bertahan dalam daya saing pada era sekarang ini. Agar tujuan perusahaan tercapai dibutuhkan SDM (sumber daya manusia) yang kompeten dan mempunyai motivasi tinggi. Pentingnya peran sumber daya manusia memiliki tujuan untuk memajukan perusahaan. Perusahaan membutuhkan sumber daya manusia yang berkualitas untuk perusahaan baik di masa sekarang hingga masa yang akan datang.

Karyawan merupakan sumber daya manusia dan salah satu faktor terpenting dalam proses produksi suatu perusahaan. Masalah ketenagakerjaan memegang peranan penting dalam kesuksesan suatu perusahaan. Oleh karena itu, perusahaan perlu membuat suatu perencanaan mengenai masalah ketenagakerjaan sesuai dengan kebutuhan setiap karyawan. Salah satu perilaku yang dapat membantu proses pemenuhn kerja perusahaan adalah perilakuOCB, (Organizational Citizenship Behavior), perilaku yang dilakukan diluar kinerja.

Banyak perilaku OCB yang terjadi dalam organisasi diarahkan untuk membantu dan memberikan dukungan kepada rekan kerja. Karyawan akan memberikan dukungan apabila rekan kerjanya mengalami kesulitan. Selain itu, karyawan dapat membantu mengatasi perbedaan pendapat yang menimbulkan konflik diantara rekan kerja dengan cara menghadapi konflik secara lebih efektif. Perilaku ini kemudian membangun hubungan yang lebih kuat di antara anggota kelompok dan bisa mengurangi kemungkinan karyawan meninggalkan organisasi (Podsakoff \& Blume, 2009).

Terdapat beberapa penelitian yang telah dilakukan, OCB dapat dipengaruhi oleh work engagement (Roberson \& Strickland, 2010), kepemimpinan transformasional (Madhu, 2005), persepsi keadilan (Moorman, 1991), usia karyawan (Wagner \& Rush, 2000), jenis kelamin (Konrad dalam Soegandhi, 2013) dan masa kerja (Baron dalam Soegandhi, 2013). Penelitian lain tentang perilaku OCB yaitu yang dilakukan oleh Nurmala (2015) menggunakan subjek 210 orang pegawai Badan Kepegawaian Negara (BKN). Hasil penelitian menunjukkan bahwa terdapat pengaruh yang signifikan dari variabel POS, Keadilan Organisasi, self-monitoring dan variabel demografi terhadap OCB.

Penelitian tentang OCB juga sudah mulai banyak dilakukan di Indonesia, diantaranya yaitu penelitian yang dilakukan oleh Susanti (2015) yang meneliti tentang hubungan religiusitas dan kualitas kehidupan kerja dengan organizational citizenship behavior (OCB). Selain religiusitas, penelitian lain yang dikaitkan dengan OCB adalah variabel kepemimpinan transformasional (Rahmi, 2014), tipe kepribadian dan komitmen oganisasi terhadap organizational citizenship behavior (Purba \& Seniati, 2004)

Perilaku OCB karyawan diperlukan untuk kemajuan perusahaan. Karyawan yang memiliki keyakinan dengan agamanya akan mendorong karyawan bersikap lebih baik dan lebih bijak di dalam perusahaan, karena hal itu menjadikan manusia mentaati perintah dan menjauhi larangan Allah SWT. Glock (1968) menjelaskan religiusitas sebagai sistem simbol, sistem kepercayaan, sistem nilai, dan perilaku yang semuanya berpusat pada persoalan-persoalan yang dihayati sebagai sesuatu yang maknawi (dalam Daniel K. Judd, 1986). Agama dapat 
mengatur perilaku manusia melalui norma dan prinsip karyawan ke dalam kehidupan kerja mereka untuk menjadikan anggota organisasi yang lebih baik (Asamani \& Mensah, 2016).

Seseorang yang merasa nyaman dan bebas mengekspresikan keyakinan dan identitas agama di tempat kerjanya kemungkinan akan mempengaruhi kepuasan, kesejahteraan, memiliki perilaku kerja dan perilaku OCB yang baik (Kutcher, 2010). Karyawan dengan religiusitas yang baik dapat mendorong karyawan bahagia dalam melakukan pekerjaannya. Maka dari itu, karyawan yang mempunyai religiusitas yang tinggi memungkinkan karyawan berperilaku OCB sehingga dapat memberikan manfaat untuk organisasi.

Asamani dan Mensah (2016), menggunakan survei cross-sectional dengan melibatkan 272 orang (125 laki-laki dan 147 perempuan) dari berbagai organisasi di wilayahGhana. $64 \%$ responden beragama Kristen, 34,3\% beragama Islam dan $1,7 \%$ kepercayaan masing-masing. Dalam penelitian ini religiusitas karyawan memiliki kontribusi yang signifikan terhadap perilaku OCB dalam organisasi. Hasil penelitian ini menunjukan bahwa upaya yang dilakukan oleh organisasi dan masyarakat pada umumnya untuk menanamkan nilai-nilai keagamaan dan sangat berharga untuk kelancaran dan efisien fungsi organisasi. Keyakinan agama membuat karyawan individu lebih sadar akan kebutuhan dan perasaan rekanrekan kerjanya dan lebih bersedia mengambil tindakan untuk kepentingan orang lain dan organisasi. Individu yang religius cenderung lebih puas dengan pekerjaan dan lebih berkomitmen terhadap nilai dan tujuan organisasi (Asamani \& Mensah, 2016).

Faktor-faktor lain yang mempengaruhi perilaku OCB adalah gaya kepemimpinan transformasional. Kepemimpinan atasan sangat berpengaruh terhadap kinerja karyawan, karyawan yang atasannya sangat baik dalam mengelola dan memimpin organisasi akan merasa nyaman dalam bekerja sehingga membuat karyawan memiliki perilaku yang dapat menguntungkan organisasi. Tipe kepemimpinan yang diperlukan untuk mendukung perilaku OCB adalah tipe atasan yang mempunyai karisma yangtinggidiantarapara bawahan, atasan yang berani mengeluarkan ide-ide kreatif yang baru, yang tentunya sangatlah diharapkan untuk mendukung tercapainya tujuan perusahaan (Syahril \& Widyarini, 2007).

Perilaku karyawan dalam suatu organisasi terkait dengan perilaku pemimpin yang memiliki dampak yang besar terhadap kinerja karyawan dan secara tidak langsung terhadap kinerja organisasi (Azeem, 2013). Karyawan yang merasa puas dengan pekerjaannya dan merasa kerja kerasnya dihargai dapat digunakan untuk memprediksi berbagai fenomena yang berkaitan dengan kepemimpinan, seperti alasan permimpin berperilaku sama seperti bawahannya atau perilaku pemimpin mempengaruhi motivasi bawahan (House, 1974). Perilaku pemimpin tidak hanya terkait dengan keinginan bawahannya, juga terkait dengan harapan bawahan bahwa usaha mereka akan menghasilkan reward yang diinginkan. Reward bergantung pada keefektifan kinerja karyawan (House, 1974).

Madhu (2005) melakukan penelitian kepada 86 manajer dan 28 mahasiswa MBA yang mempunyai pengalaman kerja di Timur India. Hasilnya menunjukkan bahwa kepemimpinan transformasional dapat meningkatkan altruism dan 
conscientiousness (general compliance) seperti dimensi yang dikemukakan oleh Smith (1983).

Selain religiusitas dan gaya kepemimpinan transformasional, faktor lain yang mempengaruhi OCB seperti demografi seperti usia dan jenis kelamin diduga memberikan pengaruh terhadap OCB. Variabel demografi telah diteliti oleh beberapa peneliti seperti variabel gender (Konrad, 2002 dalam Soegandhi 2013), variabel usia pada penelitian Wagner dan Rush (2000) dan lama bekerja (Greenberg \& Baron dalam Soegandhi 2013).

Terkait dengan variabel demografi, penelitian yang dilakukan oleh Konrad (dalam Soegandhi 2013) menyimpulkan bahwa perilaku-perilakukerjaseperti menolongoranglain, bersahabat dan bekerjasamadengan orang lain lebih menonjol dilakukan oleh wanita dari pada pria. Wagner dan Rush (2000) menjelaskan bahwa karyawan yang berusia tua memiliki pengalaman kerja yang lebih banyak dibandingkan karyawan yang muda. Greenberg dan Baron (dalam Soegandhi, 2013) mengemukakan bahwa karakteristik personal seperti masa kerja dan jenis kelamin berpengaruh terhadap OCB.

\section{METODE PENELITIAN}

\section{Populasi, Sampe dan Teknik Pengambilan Sampel}

Populasi dalam penelitian ini adalah 138 karyawan BUMN di PT. Surveyor Indonesia dan 88 karyawan swastadi Perusahaan Industri Pestisida Rumah Tangga. Teknik pengambilan sampel dalam penelitian ini adalah convenience sampling yang tergolong dalam non probability sampling.

\section{Instrumen Pengumpulan Data}

Skala yang digunakan adalah skala organizational citizenship behavior, religiusitas dan gaya kepemimpinan transformasional menggunakan model Likert dengan skala 1-5.

\section{Alat Ukur Organizational Citizenship Behavior}

Alat ukur ini didasarkan pada dua dimensi yang dikembangkan oleh C. Ann Smith, Dennis W. Organ, dan Janet P. Near (1983). Skala ini terdiri dari 16 item.

\section{Alat Ukur Religiusitas}

Alat ukur religiusitas yang akan digunakan dalam penelitian ini menggunakan skala pengukuran yang disusun oleh Huber (2012) hal ini karena alat ukur ini memiliki item dan dimensi-dimensi yang sudah dimodifikasi sebelumnya dari Glock (1968). Jumlah item dari keseluruhan dimensi berjumlah 23 item di mana keseluruhannya menggunakan skala model Likert.

3. Alat Ukur Gaya Kepemimpinan Transformasional

Alat ukur yang digunakan dalam penelitian ini menggunakan skala pengukuran yang disusun oleh Rafferty dan Griffin (2014), ) hal ini karena alat ukur ini memiliki item dan dimensi-dimensi yang sudah dimodifikasi sebelumnya dari Bass (1985) yang kemudian menghasilkan alat ukur baru yang terdiri dari 5 dimensi dan 15 item. Peneliti menggunakan alat ukur tersebut dengan menambahkan 10 item. 


\section{HASIL PENELITIAN}

\section{Gambaran Umum Subjek Penelitian}

Subyek dalam penelitian ini adalah 138 karyawan BUMN di PT. Surveyor Indonesia dan 88 karyawan swasta di Perusahaan Industri Pestisida Rumah Tangga. Gambaran umum subjek penelitian digambarkan berdasarkan ciri-ciri demografi, seperti jenis kelamin, pendidikan terakhir, jabatan, agama, usia dan lama bekerja. Pada variabel usia, nilai minimal usia $=20$ tahun, maximal $=54$ tahun, mean $=33,7124$ dan $\mathrm{SD}=7,80834$. Pada variabel lama bekerja dengan raw score, diperoleh nilai minimal sebesar $=2$ bulan, maximal $=29$ tahun, mean= 7,3839 dan $\mathrm{SD}=6,05266$

Berdasarkan tabel, terlihat bahwa subjek jumlah responden laki-laki memiliki presentase sebesar $66,8 \%$ (151 orang), responden perempuan dengan presentase $33,2 \%$ (75 orang). Pendidikan terakhir yaitu D4/S1 berjumlah 145 orang dengan presentase $64,30 \%$, selanjutnya ada SMA berjumlah 39 orang dengan presentase sebesar $17,20 \%$, D3 sebanyak 33 orang dengan presentase sejumlah $14,50 \%$ dan S2 sebanyak 9 orang dengan presentase sebesar 4,0\%.

Berikutnya dijelaskan gambaran subjek berdasarkan jabatan. Jabatan non manajerial lebih banyak mendominasi sebanyak 173 orang atau sekitar 76,55\% dan pada jabatan manajerial sebanyak 53 orang atau sekitar $23,45 \%$. Berdasarkan agama, dapat diketahui bahwa responden dalam penelitian ini didominasi yang beragama Islam sebanyak 207 orang $(91,6 \%)$, Katolik sebanyak 5 orang $(2,21 \%)$, Protestan sebanyak 12 orang $(5,31 \%)$, Hindu dan Budha hanya 1 orang $(0.44 \%)$.

\section{Tabel 1}

\section{Gambaran Umum Subyek Penelitian}

\begin{tabular}{|c|c|c|}
\hline Kategori & $\underline{\text { Jumlah }}$ & Persentase \\
\hline \multicolumn{3}{|l|}{ Jenis kelamin } \\
\hline Laki-Laki & 151 & $66,8 \%$ \\
\hline Perempuan & 75 & $33,2 \%$ \\
\hline \multicolumn{3}{|l|}{ Pendidikan terakhir } \\
\hline SMA & 39 & $17,20 \%$ \\
\hline D3 & 33 & $14,50 \%$ \\
\hline $\mathrm{D} 4 / \mathrm{S} 1$ & 145 & $64,30 \%$ \\
\hline S2 & 9 & $4,0 \%$ \\
\hline \multicolumn{3}{|l|}{ Jabatan } \\
\hline Manajerial & 53 & $23,45 \%$ \\
\hline Non manajerial & 173 & $76,55 \%$ \\
\hline \multicolumn{3}{|l|}{ Agama } \\
\hline Islam & 207 & $91,6 \%$ \\
\hline Katolik & 5 & $2,21 \%$ \\
\hline Protestan & 12 & $5,31 \%$ \\
\hline Hindu & 1 & $0,44 \%$ \\
\hline Budha & 1 & $0,44 \%$ \\
\hline Jumlah & 226 & $100 \%$ \\
\hline
\end{tabular}




\section{Hasil Uji Hipotesis}

Uji hipotesis mayor

Pada tahapan ini peneliti menguji hipotesis dengan teknik analisis regresi berganda dengan menggunakan software SPSS 20.

Tabel 2

Model Summary

\begin{tabular}{clrcc}
\hline Model & $R$ & $R$ Square & Adjusted $R$ Square & Std. Errorof theEstimate \\
\hline 1 & 0.512 & 0.262 & .217 & 8.84743 \\
\hline
\end{tabular}

a. Predictors: (Constant), intellectual, ideology, public practice, privatepractice, religious experience, visi, komunikasi inspirasional, kepemimpinan suportif, stimulasi intelektual, pengakuan personal, usia, jenis kelamin, lama bekerja.

Berdasarkan tabel di atas perolehan $R$ square sebesar 0.262 atau 26,2\%. Artinya, proporsi varians dari prokrastinasi yang dijelaskan secara bersama-sama oleh intellectual,ideology, public practice, private practice, religious experience, visi, komunikasi inspirasional, kepemimpinan suportif, stimulasi intelektual, pengakuan personal, usia, jenis kelamin, lama bekerja adalah sebesar $22.4 \%$.

\section{Anova keseluruhan IV terhadap DV}

\section{Tabel 3}

ANOVA

\begin{tabular}{lccccc}
\hline \multicolumn{1}{c}{ Model } & Sumof Squares & df & Mean Square & F & Sig. \\
\hline 1 Regression & 5905.284 & 13 & 454.253 & 5.803 & $.000^{\mathrm{a}}$ \\
Residual & 16594.716 & 212 & 78.277 & & \\
Total & 22500.000 & 225 & & & \\
\hline
\end{tabular}

a. Dependent Variable: Organizational Citizenship Behavior.

b. Predictors:(Constant), intellectual, ideology, public practice, private practice, religious experience, visi, komunikasi inspirasional, kepemimpinan suportif,stimulasi intelektual, pengakuan personal,usia, jenis kelamin, lama bekerja

Jika dilihat dapat diketahui bahwa nilai signifikansi lebih kecil ( $\mathrm{p}<0.05$ ). Maka hipotesis nihil yang menyatakan tidak ada pengaruh yang signifikan seluruh independent variable terhadap dependentvariable ditolak. Artinya, ada pengaruh yang signifikan intellectual, ideology, public practice, private practice, religiousexperience, visi,komunikasi inspirasional, kepemimpinan suportif, stimulasi intelektual, pengakuan personal, usia, jenis kelamin, lama bekerja terhadap organizational citizenship behavior.

\section{Koefisien regresi masing-masing IV}

Berdasarkan tabel koefisien regresi diatas dapat diketahui bahwa terdapat 1 variabelyang mempengaruhi secara signifikan terhadap kesiapan kerja, yaitu ketepatan waktu dengan signifikansi 0.000 . 
Tabel 4

Koefisien Regresi

\begin{tabular}{llccccc}
\hline \multirow{2}{*}{ Model } & \multicolumn{1}{c}{$\begin{array}{c}\text { Unstandardized } \\
\text { Coefficients } \\
\mathrm{B}\end{array}$} & $\begin{array}{c}\text { Standardized } \\
\text { Coeffi-cients } \\
\text { Std. Error }\end{array}$ & $\begin{array}{c}\mathrm{T} \\
\text { Beta }\end{array}$ & Sig. & & \\
\hline 1 & & 7.100 & 6.409 & & 1.108 & .269 \\
& (Constant) & .163 & .068 & .163 & 2.398 & $.017^{*}$ \\
& Intellectual & .009 & .090 & .009 & .095 & .924 \\
& Ideology & .061 & .103 & .061 & .591 & .555 \\
& Public practice & .012 & .077 & .012 & .161 & .872 \\
& Private practice & .270 & .076 & .270 & 3.559 & $.000^{*}$ \\
& Religious experience & .059 & .092 & .059 & .643 & .521 \\
& Visi & .135 & .160 & .135 & .847 & .398 \\
& Komunikasi inspirasional & .275 & .137 & .275 & 2.008 & $.046^{*}$ \\
& Kepemimpinan suportif & -.070 & .118 & -.070 & -.591 & .555 \\
& Stimulasi intelektual & -.249 & .135 & -.249 & -1.843 & .067 \\
& Pengakuan personal & .344 & .121 & .268 & 2.841 & $.005^{*}$ \\
& Usia & -.242 & 1.356 & -.011 & -.178 & .859 \\
& Jenis kelamin & -.224 & .153 & -.136 & -1.467 & .144 \\
\hline
\end{tabular}

Dependent Variable: OCB

Keterangan: signifikan (*)

\section{Proporsi Varians}

1. Variabel intellectual memberikan sumbangan sebesar 0,069 atau $6,9 \%$ dengan sig. $F$ change $=0,000$. Sumbangan tersebut signifikan.

2. Variabel ideology memberikan sumbangan sebesar 0,015 atau $1.5 \%$ dengan sig. $F$ change $=0,055$. Sumbangan tersebut tidak signifikan.

3. Variabel public practice memberikan sumbangan sebesar 0,016 atau $1,6 \%$ dengan sig. $F$ change $=0,048$. Sumbangan tersebut signifikan.

4. Variabel private practice memberikan sumbangan sebesar 0,025 atau $2,5 \%$ dengan sig. $F$ change $=0,013$. Sumbangan tersebut signifikan.

5. Variabel religious experience memberikan sumbangan sebesar 0,057 atau 5,7\% dengan sig. $F$ change $=0,000$. Sumbangan tersebut signifikan.

6. Variabel visi memberikan sumbangan sebesar 0,025 atau $2,5 \%$ dengan sig. $F$ change $=0,009$. Sumbangan tersebut signifikan.

7. Variabel komunikasi inspirasional memberikan sumbangan sebesar 0,003 atau $0,3 \%$ dengan sig. $F$ change $=0,365$. Sumbangan tersebut tidak signifikan.

8. Variabel kepemimpinan suportif memberikan sumbangan sebesar 0,004 atau $0,4 \%$ dengan sig. $F$ change $=0,273$. Sumbangan tersebut tidak signifikan.

9. Variabel stimulasi intelektual memberikan sumbangan sebesar 0,003 atau $0,3 \%$ dengan sig. $F$ change $=0,329$. Sumbangan tersebut tidak signifikan.

10. Variabel pengakuan personal memberikan sumbangan sebesar 0,008 atau $0,8 \%$ dengan sig. $F$ change $=0,131$. Sumbangan tersebut tidak signifikan.

11. Variabel usia memberikan sumbangan sebesar 0,027 atau $2,7 \%$ dengan sig. $F$ change $=0,005$. Sumbangan tersebut signifikan.

12. Variabel jenis kelamin memberikan sumbangan sebesar 0,000 atau $0 \%$ 
dengan sig. $F$ change $=0,775$. Sumbangan tersebut tidak signifikan.

13. Variabel lama bekerja memberikan sumbangan sebesar 0,007 atau $0,7 \%$ dengan sig. $F$ change $=0,144$. Sumbangan tersebut tidak signifikan.

\section{KESIMPULAN DAN SARAN}

\section{Kesimpulan}

Berdasarkan hasil penelitian, maka kesimpulan penelitian ini adalah "terdapat pengaruh yang signifikan antara variabel religiusitas, kepemimpinan transformasional usia, jenis kelamin dan lama bekerja terhadap organizational citizenship behavior (OCB)". Berdasarkan hasil uji hipotesis minor dari signifikansi masing- masing koefisien regresi terhadap dependent variable (DV), terdapat 4 variabel yang nilai koefisien regresinya signifikan, yaitu intellectual, religious experience, kepemimpinan suportifdan usia. Selain itu, terdapat 10variabel lain yang tidak signifikan diantaranya ialah ideology, public practice, private practice, visi, komunikasi inspirasional, stimulasi intelektual, pengakuan personal, jenis kelamin dan lama bekerja.

\section{Diskusi}

Berdasarkan hasil uji hipotesis yang telah dikemukakan pada bab empat, bahwa dari dimensi religiusitas (intellectual, ideology,public practice, private practice danreligious experience), dimensi gaya kepemimpinan transformasional (visi, komunikasi inspirasional, kepemimpinan suportif, stimulasi intelektual dan pengakuan personal) usia, jenis kelamin dan lama bekerja memiliki pengaruh yang signifikan terhadap organizational citizenship behavior (OCB) yakni dengan sumbangan sebesar $26,2 \%$ dan sisanya sebesar $73,8 \%$ dapat dipengaruhi oleh faktor lain.

Pada variabel religiusitas, dimensi pertama yaitu intellectual memiliki pengaruh yang signifikan terhadap perilaku OCB karyawan, artinya semakin tinggi intellectual yang dimiliki karyawan maka akan semakin tinggi juga perilaku OCB karyawan. Intellectual memiliki sumbangan sebesar 8,5\%. Penelitian ini tidak sesuai dengan penelitian yang dilakukan oleh Asamani (2016) yang menyatakan intellectual tidak memberikan pengaruh terhadap perilaku OCB.Dapat dikatakan apabila seorang karyawan memiliki pengetahuan agama yang tinggi, cara berpikir tentang agama dan religiusitas yang tinggi dapat memunculkan perilaku OCB. Karyawan mengetahui norma-norma keagamaan dan memungkinkan karyawan tersebut untuk merealisasikan norma ke dalam lingkungan organisasi.

Dimensi ideology dalam penelitian ini memberikan pengaruh yang tidak signifikan terhadap perilaku OCB karyawan. Hasil penelitian ini sejalan dengan penelitian yang dilakukan oleh Susanti (2015) yaitu tidak ada pengaruh yang signifikan antara ideology dan OCB. Karyawan yang memiliki keyakinan mengenai kebenaran dan keberadaan konsep keagamaan akan mampu memberi pengaruh terhadap karyawannya dalam berperilaku OCB. Namun dalam hasil penelitian ini, karyawan mempunyai keyakinan akanadanya Tuhan, selalu mengingat Tuhan dan menyakini agama yang dianut adalah benar. Namun dalam aktivitas pekerjaan karyawan belum maksimal mengimplikasikannya, sehingga memungkinkan karyawan tidak memperhatikan lingkungan sekitarnya.. 
Dimensi public practice dalam penelitian ini memberikan pengaruh yang tidak signifikan terhadap OCB karyawan. Penelitian ini tidak sesuai dengan penelitian Asamani (2016) yang menyatakan bahwa public practice dan OCB mempunyai pengaruh yang signifikan. Hal itu dikarenakan karyawan kurang memiliki pengetahuan keagamaan dan kurang bersosialisasi. Oleh sebab itu, dimensi publicpractice dalam penelitian ini tidak memberikan pengaruh yang signifikan terhadap OCB.

Dimensi private practice dalam penelitian ini memberikan pengaruh yang tidak signifikan terhadap OCB karyawan. Penelitian ini tidak sesuai dengan penelitian Asamani (2016) yang menyatakan bahwa private practice dan OCB mempunyai pengaruh yang signifikan. Hal ini dapat terjadi karena tidak semua karyawan yang mengikuti kegiatan keagamaan secara individu seperti berdoa, memiliki keyakinan yang kuat terhadap Tuhan. Karyawan mempunyai pola berpikir bekerja adalah suatu kebutuhan bukan karena ibadah.

Dimensi religious experience dalam penelitian ini memberikan pengaruh yang signifikan terhadap OCB. Hasil penelitian ini sesuai dengan penelitian yang dilakukan Asamani (2016). Dimensi ini menyumbang sebesar $20.1 \%$ artinya, semakin tinggi skor religious experience karyawan maka semakin tinggi pula perilaku OCB. Hal ini dapat terjadi dikarenakan karyawan mempunyai pengalaman agama dan perasaan religius. Pengalaman keagamanan karyawanmenjadi dasar-dasar dari perilaku OCB, dimana suatu akhlak dapat dilihat dari perilaku yang ditunjukan. Meliputi rasa keikhlasan dalam menolong, bekerja dan juga beribadah, melakukan ibadah sematamata karena Tuhan dan berharap keridhoan-Nya, sehingga perilaku bekerja dapat dilakukan secara sukarela tidak berdasarkan reward atau punishment sangat membutuhkan suatu keikhlasan dalam menolong (Susanti, 2015).

Pada variabel kepemimpinan transformasional, dimensi pertama yaitu visi dalam penelitian ini memberikan pengaruh yang tidak signifikan terhadap OCB. Ketika karyawan merasa bahwa pemimpin bersikap adil dan ketika perilaku pemimpin dikaitkan dengan niat baik pemimpin dan apabila karyawan merasa apabila pemimpinnya mempunyai tujuan kedepan untuk organisasinya, karyawan cenderung menyimpulkan bahwa pemimpin mereka berkomitmen terhadap mereka. Sebaliknya, pemimpin yang tidak memiliki karakteristik visi yang baik tidak mampu memberikan arahan yang jelas kepada bawahannya. Pemimpin tidak bersikap adil kepada bawahannya, adanya batasan antara pemimpin dan bawahan, sehingga bawahan tidak termotivasi untuk mencapai tujuan organisasi. Hal itu yang menyebabkan karyawan kurang berperilaku OCB. Hasil penelitian ini sejalan dengan penelitian yang dilakukan oleh Cem GÜÇEL (2012) yaitu tidak ada pengaruh yang signifikan antara visi dan OCB.

Variabel komunikasi inspirasional dalam penelitian ini memberikan pengaruh yang tidak signifikan terhadap OCB. Hasil ini tidak sesuai dengan penelitian yang dilakukan oleh oleh Muhammad Waqaz Azeem (2013). Hasil penelitian inikomunikasi inspirasional tidak memberikanpengaruh terhadap OCB. $\mathrm{Hal}$ inidikarenakan, pemimpin masih kurangmemberikan motivasi dan rasa percaya diriuntuk bawahannya. Pemimpinnya menjadipendengar tanpa memberikan saran yang positif untuk kemajuan organisasi. 
Variabel stimulasi intelektual dalam penelitian ini memberikan pengaruh yang tidak signifikan terhadap OCB. Pemimpin yang terus menerus menuntut karyawannya untuk berpikir kreatif dan inovatif dapat mengakibatkan karyawan merasa stress dan tertekan, sehingga membuat karyawan kurang berperilaku OCB. Hal itu yang menyebabkan stimulasi intelektual memberikan pengaruh yang negatif terhadap OCB. Hasil penelitian ini sejalan dengan penelitian yang dilakukan oleh Nguni dkk (2006) yaitu tidak ada pengaruh yang signifikan stimulasi intelektual dan OCB.

Variabel kepemimpinan suportif dalam penelitian ini memberikan pengaruh yang signifikan terhadap OCB. Dimensi ini menyumbangkan $21.6 \%$ artinya, semakin tinggi skor kepemimpinan suportif maka semakin tinggi pula perilaku OCB karyawan. Menurut House dkk (1973), pemimpin yang suportif adalah pemimpin yang ramah, mudah dekat dengan bawahannya, menunjukkan kepedulian terhadap status, kesejahteraan dan kebutuhan bawahannya. Pemimpin melakukan hal-hal kecil untuk membuat pekerjaan lebih menyenangkan dan memperlakukan bawahan adil dan bersahabat. Pemimpin mendukung karyawannya agar bisa maju, berkembangdan mengajak karyawan untuk memajukan organisasi secara bersama-sama, hal itu menyebabkan karyawan merasa dihargai oleh atasannya. Hasil penelitian ini sejalandengan penelitian yang dilakukan olehMadhu (2005) yang menyatakan bahwakepemimpinan suportif memberikan pengaruh yang signifikan terhadap perilakuOCB.

Variabel pengakuan personal dalam penelitian ini memberikan pengaruh yang tidak signifikan terhadap OCB. Hasil penelitian ini tidak sesuai dengan hasil penelitian yang dilakukan oleh Muhammad Waqaz Azeem (2013) yang menyatakan bahwa pengakuan personal mempunyai pengaruh terhadap perilaku OCB. Pemimpin yang tidak memonitor karyawannya dan tidak memberikan penghargaan atas dedikasi yang dilakukan oleh karyawan menyebabkan karyawan kurang berperilaku OCB karena merasa tidak dihargai oleh atasan.

Variabel usia dalam penelitian ini memberikan pengaruh yang signifikan sebesar 23,3\% terhadap OCB. Hal ini berarti semakin tinggi usia seseorang maka semakin tinggi juga perilaku OCB seseorang, begitupun sebaliknya. Hasil penelitian ini sejalan dengan penelitian yang dilakukan oleh Jahangir (2004) yaitu ada pengaruh yang signifikan antara usia dan OCB. Menurut Wagner dan Rush (2000) hal itu bisa disebabkan karena karyawan yang lebih tua merasa banyak memiliki pengalaman di lingkungan kerja dibandingkan dengan rekan kerja mereka yang lebih muda, alasan lainnya yaitu karyawan yang lebih tua lebih berkontribusi untuk membantu organisasi mereka dibandingkan karyawan yang muda.

Variabel jenis kelamin dalam penelitian ini tidak memberikan pengaruh yang signifikan. Hasil penelitian ini sejalan dengan penelitian yang dilakukan oleh Su Fen Chiu (2006). Hal ini dikarenakan antara karyawan perempuan dan lakilaki mempunyai kesetaraan yang sama dan tidak ada perbedaan, sehingga jenis kelamin tidak mempengaruhi perilaku OCB karyawan. Hasil dalam penelitian ini bertolak belakang dengan penelitian yang dilakukan oleh Allen (2001) yang menyatakan bahwa jenis kelamin mempunyai pengaruh yang signifikan terhadap perilaku OCB karyawan. 
Variabel lama bekerja dalam penelitian ini tidak memberikan pengaruh yang signifikan terhadap OCB. Hasil penelitian ini sejalan dengan hasil penelitian yang dilakukan oleh Kamel dkk (2015) yang mengatakan bahwa lama bekerja dan OCB tidak mempunyai pengaruh yang signifikan. Menurut soegandhi (2013) karyawan yang telah lama bekerja akan memiliki kedekatan dan keterikatan yang kuat dengan organisasi. Masa kerja yang lama juga akan meningkatkan rasa percaya diri dan kompetensi karyawan dalam melakukan pekerjaannya, serta menimbulkan perasaan dan perilaku positif terhadap organisasi yang mempekerjakannya. Sebaliknya, pada penelitian ini karyawan baru lebih memiliki semangat kerja dibandingkan karyawan yang sudah lama bekerja. Apabila karyawan yang telah lama bekerja tidak merasakan kedekatan maupun keterikatan yang kuat terhadap organisasinya akan mengurangi rasa percaya diri mereka dan kurang mengeluarkan kompetensi mereka. Hal itu yang menyebabkan masa kerja memberikan pengaruh yang negatif terhadap OCB. Hasil penelitian ini bertolak belakang dengan hasilpenelitian yang dilakukan oleh Van Dyne (1994) bahwa lama bekerja mempunyai pengaruh yang signifikan terhadap OCB.

\section{Saran}

Pada penelitian ini ditemukan bahwa proporsi varians dari OCB yang dijelaskan oleh semua IV adalah sebesar $26.2 \%$, sedangkan $73.8 \%$ sisanya dipengaruhi oleh variabel lain di luar penelitian ini, maka penulis menyarankan untuk penelitian selanjutnya agar meneliti dan menganalisis pengaruh variabel di luar variabel yang telah diteliti agar lebih luas dalam gambaran penelitiannya. Kemudin pada penelitian ini, sampel yang digunakan yaitu 226 karyawan yang terdiri dari 138 karyawan BUMN dan 88 karyawan swasta, oleh karena itu pada penelitian selanjutnya disarankan untuk penelitian antara karyawan BUMN dan karyawan swasta menggunakan sampel yang seimbang. Terakhir pada penelitian selanjutnya disarankan untuk mencari sampel selain karyawan BUMN dan swasta misalnya manajer restoran (mengacu pada penelitian Becker, 1994), guru (mengacu pada penelitian Bogler, 2005), resepsionis hotel (mengacu pada Soo Kim dkk, 2010).

\section{DAFTAR PUSTAKA}

Allen, T. D., \& Rush, M. C. (2001). The influence of ratee gender on ratings of organizational citizenship behavior. Journal of Applied Social Psychology, 31(12), 2561-2587.

Antonakis, J., \& Avolio, N. S. (2003). Context and leadership: An exmination of the nine-factor full-range leadership theory using the multifactor leadership questionnaire. The Leadership Quartely, 14, 261-295. DOI: 10.1016/S10489843(03)00030-4

Asamani, L., \& Mensah, A. O. (2016). Religiousity as an antecedent of employee's organizational citizenship behavior. Advances in Social Sciences Research Journal, 3(7), 34-45. DOI:10.14738/assrj.37.2074

Asgari, A., \& Bahaman Abu Sama, A. D. (2008). The relationship between transformational leadership behaviors, leader-member exchange and organizational citizenship behaviors. European Journal of Social Sciences, 6(4), 
140-150.

Azeem, M. W. (2013). Organizational citizenship behaviors in small and medium enterprises in the context of leadership behavior. Pakistan: Bachelorarbel.

Bass, B. M., \& Riggio, R. E. (2006). Transformational leadership. London: Lawrence Erlbraum Associates.

Becker, T. E., \& Randall, D. M. (1994). Validation of a measure of organizational citizenship behavior against an objective behavioral criterion. Sage. 54(1). 160-167. DOI: $10.1177 / 0013164494054001021$.

Bogler, R., \& Somech, A. (2005). Organizational citizenship behavior in school. Emerald Insightt, 43(5). 420-438. DOI: 10.1108/09578230510615215.

Chiu, S.-F., \& Tsai, M.-C. (2006). Relationship among burnout, job involvement, and organizational citizenship behavior. The Journal of Psychology, 140(6). 517-530. DOI: $10.3200 / J R L P .140 .6 .517-530$

C., A. S., Organ, D. W., \& Near, J. P. (1983). Organizational citizenship behavior: Its nature and antecedents. Journal of Applied Psychology, 68(4). 653-663. DOI: 10.1037/0021-9010.68.4.653

Cho, J., \& Danserau, F. (2010). Are transformational leaders fair? A multi-level study of transformasional leadership, justice peceptions, and organizational citizenship behavior. The Leadership Quartely. 21, 409-421. DOI:10.1016/j.leaqua.2010.03.006

Daniel K. Judd, M. (1986). Religious affiliation and mental health. AMCAP Journal, 12(2), 71-108.

Darto, M. (2014). Peran organizational citizenship behavior (OCB) dalam peningkatan kinerja individu di sektor publik: Sebuah analisis teoritis dan empiris. Jurnal Borneo Adminstrator, 10(1), 10-30.

Dyne, L. V., \& Graham, R. M. (1994). Organizational citizenship behavior: Construct redefinition, measurement, and validation. Academy of Management Journal, 37(4). 765-802.

E.King, J., \& Williamson, I. O. (2010). Workplace religous expression, religiosity and job satisfaction: Clarifying a relationshop. Journal of Management, Spirituality \& Religion, 2(2), 173-198. DOI: 10.1080/147666080509518579

Farh, J.-L., \& Earley, S.-C. L. (1997). Impetus for action: A cultural analysis of justice and organizational citizenship behavior in Chinese society. Sage Publications, 42(3). 421-444.

Fetzer, J. E. (1999). Measurement of religiousness, spirituality for use in health research. Michigan: John E. Fetzer Institute.

Floyd, F. J., \& Widaman, K. F. (1995). Factor analysis in the development and refinement of clinical assesment instruments. American Psychological Association, 79(3). 286-299.

Gucel, C., \& Begec, S. (2012). The effect of the servant leadership on organizational citizenship behavior: Case study of a university. International Journal of Social Sciences and Humanity Studies, 4(1).107-116.

House, R. J., \& Mitchell, T. R. (1974). Path goal theory of leadership. Seattle: Organizational Research.

H.Moorman, R., \& Blakely, G. L. (1995). Individualism, collectivism as an 
individual difference predictor of organizational citizenship behavior. Journal of Organizational Behavior, 16(2). 127-142. DOI: 10.1002/job.4030160204

Huber, S., \& Huber, O. W. (2012). The centrality of religiosity scale (CRS). Religions, 710-724.

Jahangir, N. (2004). Organizational citizenship behavior; Its nature and antecedents. BRAC University Journal, 1 (2), 75-85.

Kamel, B., \& Ilyas, S. Z. (2015). Relationship between demographic characteristics organizational citizenship behavior in the national company for distribution of electricity and gas. International Journal of Innovative Research in Engineering \& Management, 7 (6). 8-11.

Kendler, K. S., \& et.al. (2003). Dimension of religiosity and their relationship to lifetime psychiatrice and substance use disorders. Psychiatric, 160(3), 406503.

Kim, S., \& O'Neill, H.-M. C. (2010). When does an employee not help coworkers? The effect of leader-member exchangeon employee eny and organizationa citizenship behavior. International Journal of Hospitality Management, 530-537. Doi: 10.1016/j.ijhm.2009.08.003.

Komalasari, P. T., \& Nasih, T. P. (2009). Pengaruh public service motivation dan organizational citizenship behavior terhadap kinerja organisasi pemerintahan. Jurnal Manajemen Teori dan Terapan, 2(2), 128-141.

Kutcher, E. J. (2010). The role of religiosity in stress, job attitudes, and organizational citizenship behavior. Journal of Business Ethics, 95:319-337. DOI: $10.1007 / \mathrm{s} 10551-009-0362-\mathrm{z}$

Madhu, B., \& Krishnan, V. R. (2005). Impact of transformational leadership and karma-yoga on organizational citizenship behavior. Prestige Journal of Management and Research, 9 (1). 1-20.

Martin, C. A., \& Bush, A. J. (2003). The potential influence of organizational and personal variables on customer-oriented selling. Journal of Business \& Industrial Marketing, 18(2). 114-132. DOI: 10.1108/08858620310463051

Moorman, R. H. (1991). Relationship between organizational justice and organizational citizenship behaviors: Do fairness perceptions influence employee citizenship? Journal of Applied Psychology, 76(6), 845-855. DOI:10.1037/00219010.76.6.845

Motowidlo, S. J., \& Scotter, J. R. (1994). Evidence that task performance should be distinguished from contextual performance. American Psychological Association, 79 (4). 475-480.

Muchinsky, P. M. (2000). Psychology applied to work. Stamford: Wadsworth.

Nguni, S., \& Sleegers, E. D. (2006). Transfomational and transactional leadership effects on teachers' job satisfaction, organizational commitment, and organizational citizenship behavior in primary schools: The Tanzanian case. Routledge, 17(2). 145-177. DOI: 10.108009243450600565746

Nurmala, K. (2015). Perceived organizational support (pos), keadilan organisasi dan self monitoring sebagai prediktor ocb. Jakarta: UIN Syarif Hidayatullah Jakarta. 
Organ, D. W., \& Podsakoff, S. B. (2006). Organizational citizenship behavior: Its nature, antecedents and consequences. California: Sage Publications.

Pedhazur, E. (1982). Multiple regression in behavioral research: Explanation and prediction second edition. USA: CBS Collage Publishing

Podsakoff, P. M., Paine, S. B., \& Bachrach, D. G. (2000). Organizational citizenship behaviors: A critical review of the theoretical and empirical literature and suggestions for future research. Journal of Management, 26(3), 513-563. DOI: 10.1177/014920630002600307.

Podsakoff, N. P., \& Blume, S. W. (2009). Individual- and organizational-level consequences of organizational citizenship behavior: A meta-analysis. Journal of Applied Psychology, 94(1), 122-141. DOI: 10.1037/a0013079

Pranata, J. (2016). Uji validitas konstruk leader member exchangemultidimensional measure (LMX-MDM). Jurnal Pengukuran Psikologi, 5(1).73-86

Prihatsanti, U., \& Dewi, K. S. (2010). Hubungan antara iklim organisasi dan organizational citizenship behavior (OCB) pada guru SD Negri di kecamatan Mojolaban Sukoharjo. Jurnal Psikologi Undip, 7(1), 11-16.

Purba, D. E., \& Seniati, A. N. (2004). Pengaruh kepribadian dan komitmen organisasi terhadap organizational citizenship behavior. Jurnal Social Humaniora, 8(3), 105-111.

Rafferty, A. E., \& Griffin, M. A. (2004). Dimensions of transformational leadership: Conceptual and empirical extensions. The Leadership Quartely, 15(2004), 329-354. DOI:10.1016/j.leaqua.2004.02.009

Rahmi, B. M. (2014). Pengaruh kepemimpinan transformasional terhadap organizational citizenship behavior dan komitmen organisasional dengan mediasi kepuasan kerja. Jurnal Manajemen Universitas Udayana, 331-350.

Riggio, R. E. (2012). Introduction to industrial organizational. PearsonRoberson, M. E., \& Strickland, O. J. (2012). The relationship between charismatic leadership, work engagement, and organizational citizenship behavior. Journal of Psychology, 144(3), 313-326. DOI: 10.1080/00223981003648336

Roberson, M. E., \& Strickland, O. J. (2010). The relationship between charismatic leadership, work engagement, and organizational citizenship behavior. Journal of Psychology, 144(3), 313-326.

Sandra, D. (2011). Kontribusi komitmen organisasi dan kepemimpinan transformasional terhadap organizational citizenship behavior pada PT. Carrefour Indonesia. Gunadarma, 1-15.

Soegandhi, V. M., Sutanto, E. M., \& Setiawan, R. (2013). Pengaruh kepuasan kerja dan loyalitas kerja terhadap organizational citizenship behavior pada karyawan PT. Surya Timur Sakti Jatim. AGORA, 1(13), 1-12.

Stark, R., \& Glock, C. Y. (1968). American piety: The nature of religious commitment. London: University of California Press.

Susanti, R. (2015). Hubungan Religiusitas dengan OCB. Jurnal Psikologi, 11(2), 94103

Syahril, N., \& Widyarini, M. N. (2007). Kepribadian, kepemimpinan 
transformasional dan perilaku kewargaorganisasian. Jurnal Psikologi, 1(1), 40-46.

Wagner, S. L., \& Rush, M. C. (2000). Altruistic organizational citizenship behavior: Context, disposition, and age. The Journal of Psychology, 140(3), 379-391. DOI: 10.1080/00224540009600478

Wibowo, U. D., \& Dewi, D. S. (2016). The role of religiosity on organizational citizenship behavior employee of Islamic banking. Jurnal UMJ, 1235-1239.

Yukl, G. (1999). An evaluation of conceptual weakness in transformational and charismatic leadership theories. Leadership Quartely, 10(2). 285-305. DOI: 10.1016/S1048-9843(99)00013-2 
The Effect of Religiusity, Tranformational Leadership and Demography on OCB 